\title{
BMJ Open A systematic review and meta-analysis assessing adverse event profile and tolerability of nicergoline
}

\author{
Mario Fioravanti, ${ }^{1}$ Taku Nakashima, ${ }^{2}$ Jun $\mathrm{Xu},{ }^{3}$ Amit Garg ${ }^{4}$
}

To cite: Fioravanti $M$, Nakashima T, Xu J, et al. A systematic review and metaanalysis assessing adverse event profile and tolerability of nicergoline. BMJ Open 2014;4:e005090.

doi:10.1136/bmjopen-2014005090

- Prepublication history and additional material is available. To view these files please visit the journal (http://dx.doi.org/10.1136/ bmjopen-2014-005090).

Received 20 February 2014 Revised 5 June 2014 Accepted 11 July 2014

CrossMark

For numbered affiliations see end of article.

Correspondence to Dr Amit Garg;

amitgarg.pharm@gmail.com

\section{ABSTRACT}

Objective: To evaluate the safety profile of nicergoline compared with placebo and other active agents from published randomised controlled trials.

Design: Systematic review and meta-analysis of nicergoline compared with placebo and other active agents across various indications.

Data sources: MEDLINE, Medline-in-process, Cochrane, EMBASE, EMBASE alerts, Cochrane Central Register of Controlled Trials (CENTRAL), Cochrane Database of Systematic Reviews (CDSR) and Cochrane Methodology Register (CMR) for all the randomised controlled trials, open-label or blinded, in adults treated with nicergoline. Studies published until August 2013 were included.

Review method: 29 studies were included for data extraction. The studies included in this review were majorly from European countries and mostly in cerebrovascular disease $(n=15)$ and dementia $(n=8)$.

Results: The treatment withdrawals were comparatively lower in the nicergoline group as compared with the placebo group ( $\mathrm{RR}=0.92 ; 95 \% \mathrm{Cl} 0.7$ to 1.21 ) and other active comparators (RR $=0.45 ; 95 \% \mathrm{Cl} 0.10$ to 1.95 ), but the difference was non-significant. Incidence of any adverse events (AEs) was slightly higher ( $R R=1.05 ; 95 \% \mathrm{Cl}$ 0.93 to 1.2) while incidence of serious AEs was lower ( $\mathrm{RR}=0.85 ; 95 \% \mathrm{Cl} 0.50$ to 1.45 ) in the nicergoline compared with placebo group. Frequency of anxiety was significantly lower in nicergoline as compared with placebo $(\mathrm{p}=0.01)$. Other AEs including diarrhoea, gastric upset, dizziness and drowsiness were less frequent in the nicergoline group when compared with placebo/active drugs, but the difference was non-significant. Frequency of hypotension and hot flushes was slightly higher in the nicergoline group but the difference was non-significant. None of the studies reported any incidence of fibrosis or ergotism with nicergoline treatment.

Conclusions: Nicergoline is an ergot derivative, but its safety profile is better than other ergot derivatives like ergotamine and ergotoxine. This systematic review and meta-analysis suggests that nicergoline has a good safety profile. None of the studies included in this systematic review reported any incidence of fibrosis or ergotism with nicergoline.

\section{BACKGROUND}

Nicergoline is a semisynthetic ergot derivative which has been registered in over 50

\section{Strengths and limitations of this study}

- First meta-analysis on nicergoline to understand the adverse clinical profile.

- Critical in wake of recent European Medicines Agency's (EMEA) view of blanket limitation on use of all ergot derivatives.

- Limited by the availability of long-term (more than 2 years) and high-dose studies for cognitive impairment.

countries and has been used for more than four decades for the treatment of cognitive, affective and behavioural disorders in older people. ${ }^{1}$ During the time it has been in use, the rationale for its clinical use has evolved. Initially regarded as a vasoactive drug, it was mainly prescribed for cerebrovascular disorders. Although cholinergic deficits are the major current targets for pharmacological intervention in Alzheimer's dementia, a wide variety of other neurotransmitter changes can be identified in the disease.

Nicergoline has been demonstrated to increase the availability of acetylcholine through an increased release from cholinergic terminals and a selective inhibition of acetyl cholinesterase. ${ }^{2}$ Nicergoline may also enhance norepinephrine and dopamine turnover in some areas of the brain. ${ }^{3}$ Nicergoline has a positive effect on the signal transduction system stimulating the phosphoinositide pathway which is specifically impaired in Alzheimer's dementia. ${ }^{4}$ Other useful actions of nicergoline in dementia are an increase of phosphoinositide-protein kinase $\mathrm{C}(\mathrm{PKC})$ translocation which helps in combating $\beta$-amyloid deposition and in retarding the reduction in nerve-growth factor which may help in preventing the loss of cholinergic neurons. ${ }^{4}$

The side effects of nicergoline are usually limited to nausea, hot flushes, mild gastric upset, hypotension and dizziness. At high dosages bradycardia, increased appetite, agitation, diarrhoea and perspiration have been 
known to occur. Nicergoline has a better safety profile compared with ergot derivates which are associated with increased risk of fibrosis (formation of excess connective tissue that can damage organs and body structures) and ergotism (symptoms of ergot poisoning, such as spasms and obstructed blood circulation) with these medicines.

Nicergoline is not associated with either fibrosis or ergotism; however, concerns about its safety have been raised, especially after the European Medicines Agency's (EMEA) restriction on nicergoline, because it is an ergot derivative. ${ }^{5}$ Most of the available literature suggests that the adverse events (AEs) with nicergoline are mild and transient. Hence, a systematic review of literature and meta-analysis was conducted to compare the safety profile of nicergoline with placebo and other active comparators.

\section{METHODS}

\section{Search strategy}

A comprehensive search strategy was designed to retrieve relevant clinical data from published literature. The following databases were examined since inception up to 16 August 2013; MEDLINE, Medline-in-process, EMBASE, EMBASE alerts, Cochrane Central Register of Controlled Trials (CENTRAL), Cochrane Database of Systematic Reviews (CDSR) and Cochrane Methodology Register. Medical subject headings (MeSH terms) and free keywords like "randomised controlled trial", "Nicergoline", "Adverse effects", "toxicity" and "side effects" were used (see online supplementary appendix 1). This review was not restricted to studies conducted in the English language and hence studies published in other languages were also included and translated for data extraction.

\section{Selection criteria}

To meet the study objective, we predecided on inclusion criteria which include randomised controlled trials (RCTs) reporting AEs in patients undergoing nicergoline treatment for psychiatric disorders. To be included in the analysis, a trial had to fulfil the following criteria: (1) randomised trials which could be open-label, singleblind or double-blind, parallel group studies; (2) use of nicergoline for Alzheimer's disease, dementia or cognitive disorders; (3) use of nicergoline as one of the interventions; (4) studies comparing nicergoline with ergot derivatives, placebo or other active agents were included and (5) studies should report safety and tolerability data for nicergoline.

Studies were excluded if: (1) they presented data on children only; (2) study design was not of interest; (3) disease was other than of interest; (4) study was not presenting safety and tolerability outcomes and (5) full text could not be sourced.

\section{Data extraction}

Bibliographic details and abstracts of all citations retrieved by the literature search were downloaded into
Endnotes V.X3. Cochrane methodology was used to conduct this systematic review. All studies were screened by two independent reviewers with discrepancies resolved by a third reviewer.

\section{Study quality and risk of bias}

The Jadad score was used to assess the quality of included studies. Risk of bias in the individual studies included for meta-analysis was assessed using the Cochrane risk assessment tool. ${ }^{6}$

\section{Outcomes assessed}

In most of the included studies, safety evaluation included monitoring of AEs, vital signs, haematology and blood chemistry. Haematology and blood chemistry were assessed at baseline and at the last assessment. Tolerability evaluation included monitoring of treatment-emergent AEs (elicited or observed); physical examination including ECG recording; vital signs, haematology and blood chemistry testing. Withdrawals, due to any reason or due to $\mathrm{AE}$, were reported.

The data from these studies were pooled for total withdrawals, withdrawals due to AEs, incidence rates for any AEs, serious AEs (SAEs) and specific AEs including anxiety, constipation, diarrhoea, hot flushes, itching, gastric upset, hypotension, headache, dizziness, insomnia, drowsiness and fatigue. Only studies which presented data for same comparators were included in direct meta-analysis for each outcome.

\section{Statistical analysis}

Comparison of safety and tolerability outcomes was made between interventions by pooling data from studies using a direct meta-analysis technique. Only head-to-head comparisons between interventions were included for meta-analysis. Review Manager (RevMan V.5.1) software was used for meta-analysis of the available data. Dichotomous outcomes were summarised as risk (relative) ratios.

\section{RESULTS}

\section{Study selection}

A trial flow of the review process (as per PRISMA statement) is presented along with manuscript (figure 1). The search of the literature yielded 437 separate references. Owing to the overlap of coverage between the databases, 96 of the references were found to be duplicates. A total of 341 citations were reviewed for abstract screening (first pass). Following the first pass of the citations, 56 potentially relevant references were identified. Full-text reports of these citations were obtained for more detailed evaluation. Following detailed examination of the reports, 26 citations were excluded. Thirty studies met inclusion criteria; however, one of them was a secondary publication which was linked to its primary publication. Finally, a total of 29 references reporting trials were extracted. Table 1 presents an overview of the study methods in included studies. Fifteen studies were 
Figure 1 PRISMA flow for included studies.

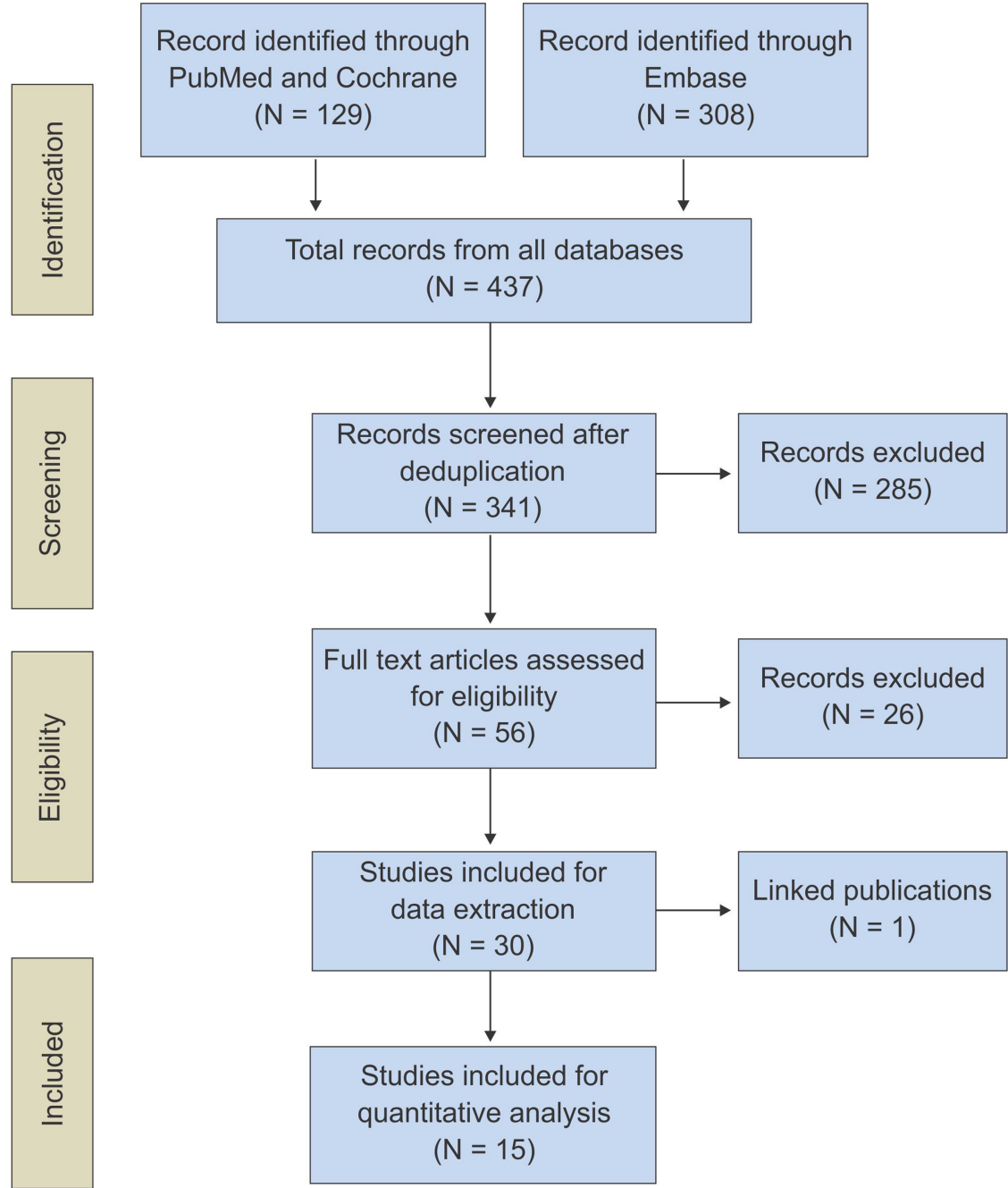

not included in meta-analysis as data from these could not be pooled. These were studies reporting stand-alone AEs, or for stand-alone comparators.

\section{Baseline characteristics}

Most of the included studies were in cerebrovascular disease $(n=15)$, followed by dementia $(n=8)$. Two studies were for Alzheimer's disease and four were in other disease areas. The mean age of included patients ranged from $48^{17}$ to 81 years ${ }^{32}$ across the studies. The percentage of male patients ranged from $17.9 \%{ }^{32}$ to $76.7 \%^{26}$ in the nicergoline group and was comparable with the control group in all studies. The number of patients randomised in these studies ranged from $16^{31}$ to $346^{34}$. The treatment/study duration ranged from 6 days ${ }^{31}$ to 24 months $^{11}$ across included studies with most studies with duration $\geq 3$ months $(n=17)$. The daily dose of nicergoline used was $\leq 30 \mathrm{mg} /$ day in 16 studies and was reported to be $60 \mathrm{mg} /$ daily in 12 studies.

\section{Critical appraisal}

Included studies were critically appraised using the Jadad scale which is a standard scale used for evaluating the quality of randomised trials in systematic reviews.
Methods used to generate random allocation sequences were reported in only nine of the included studies and were judged as adequate. The Jadad score was $\geq 3$ in 20 studies and less than 3 in 9 studies. The majority of the studies were good quality studies as per the Jadad scale. All of the included studies reported comparable baseline characteristics between treatment groups being studied.

\section{Risk of bias assessment}

The risk of bias was low in the individual studies that were included for meta-analysis. The method used to generate the allocation sequence was reported in sufficient detail to allow an assessment in most of the studies. None of the included studies reported any inadequate method. The method used for allocation concealment was not reported by any of the included studies. The method used for blinding was adequate in most of the studies reporting it. Studies of withdrawals and patients' inclusion for outcome assessments were similar within study groups.

\section{Withdrawals}

Total withdrawals with nicergoline ranged from $0 \% 2225$ to $22.2 \%^{11}$ and from $0 \%$ to $27.8 \%$ with other 
Table 1 Study methods for included randomised controlled trials

\begin{tabular}{|c|c|c|c|c|c|c|}
\hline Study name & $\begin{array}{l}\text { Study } \\
\text { duration }\end{array}$ & Country & Blinding & Intervention & Comparator & $\begin{array}{l}\text { Daily dose of } \\
\text { nicergoline }(\mathrm{mg})\end{array}$ \\
\hline Arrigo et al & 14 weeks & Italy & Double-blind & Nicergoline & Placebo & 60 \\
\hline Battaglia et $a \beta$ & 6 months & Italy & Double-blind & Nicergoline & Placebo & 60 \\
\hline Battaglia et a $\rho$ & 6 months & Italy & Double-blind & Nicergoline & Ergot mesylates & 60 \\
\hline Battaglia et $a 1^{10}$ & 12 months & Italy & Double-blind & Nicergoline & Placebo & 60 \\
\hline Bes et $a l^{11}$ & 24 months & France & Double-blind & Nicergoline & Placebo & 60 \\
\hline Bossi $^{12}$ & - & Italy & Double-blind & Nicergoline & Buflomedil & 8 \\
\hline Brola $^{13}$ & 1 month & Poland & Single-blind & Nicergoline & Pentoxifylline & 30 \\
\hline Cascone et $a l^{14}$ & 1 month & Italy & Double-blind & Nicergoline & Placebo & 15 \\
\hline $\begin{array}{l}\text { Colombeau and } \\
\text { Ballanger }{ }^{15}\end{array}$ & 15 days & France & Double-blind & Nicergoline & Placebo & 40 \\
\hline Crook $^{16}$ & 6 months & USA & Double-blind & Nicergoline & Placebo & 60 \\
\hline Dubreuil $^{17}$ & 1 month & France & Double-blind & Nicergoline & GBE & NR \\
\hline Felisati et al/ ${ }^{18}$ & 3 months & Italy & Double-blind & Nicergoline & Placebo & 60 \\
\hline Forette et $a l^{19}$ & 3 weeks & France & Double-blind & Nicergoline & Placebo & 30 \\
\hline Gessner et a ${ }^{20}$ & 12 weeks & Germany & Double-blind & Nicergoline & GBE & 15 \\
\hline Herrmann ${ }^{21}$ & 6 months & Germany & Double-blind & Nicergoline & Placebo & 60 \\
\hline $\begin{array}{l}\text { Kugler and } \\
\text { Meurer-Krull }^{22}\end{array}$ & 6 months & Germany & Double-blind & Nicergoline & Dihydroergotamine & 30 \\
\hline $\mathrm{Lu}^{23}$ & 12 weeks & China & Double-blind & Nicergoline & Aniracetam & 60 \\
\hline Marolda et $a P^{4}$ & 20 days & Italy & Double-blind & Nicergoline & Eburnamonine & $15-20$ \\
\hline Materna ${ }^{25}$ & 12 weeks & Germany & Double-blind & Nicergoline & Flunarizine & $10-30$ \\
\hline Nakashima et $a^{p 6}$ & 6 months & Japan & Double-blind & Nicergoline & Imidapril & 15 \\
\hline Nappi et $a^{R^{7}}$ & 12 months & Italy & Double-blind & Nicergoline & Placebo & 60 \\
\hline Nishiyama et $a^{88}$ & 4 weeks & Japan & Open-label & Nicergoline & Placebo & 45 \\
\hline Pilkowska et a ${ }^{p 9}$ & 3 months & Poland & Double-blind & Nicergoline & Placebo & 60 \\
\hline Pogliani $1979^{30}$ & 3 months & Germany & Double-blind & Nicergoline & Placebo & 15 \\
\hline Ronchi et $a \beta^{\beta 1}$ & 6 days & Italy & Double-blind & Nicergoline & Placebo & \\
\hline Saletu et $a \beta^{2}$ & 8 weeks & Austria & Double-blind & Nicergoline & Placebo & $30-60$ \\
\hline Setyopranoto et $a^{\beta 3}$ & - & Indonesia & Double-blind & Nicergoline & Placebo & 60 \\
\hline Winblad et $a^{\beta 4}$ & 6 months & Europe & Double-blind & Nicergoline & Placebo & 60 \\
\hline $\begin{array}{l}\text { Zucconi and Terzi } \\
\text { Bolaffio }^{35}\end{array}$ & 1 month & Italy & Double-blind & Nicergoline & Dihydroergotoxine & 2 intramuscular \\
\hline
\end{tabular}

comparator drugs/placebo. Six studies reported a lower number of patient withdrawals from the nicergoline group as compared with other comparator/placebo groups. Withdrawals due to $\mathrm{AE}$ were similar in the nicergoline group as compared with other groups across the studies (figure 2).

The meta-analysed risk ratios between nicergoline and the other comparators and their corresponding $95 \%$ CIs

\begin{tabular}{|c|c|c|c|c|c|c|c|c|c|c|c|}
\hline \multirow[b]{2}{*}{ Study or Subgroup } & \multicolumn{2}{|c|}{ Nicergoline } & \multicolumn{2}{|c|}{ Placebo } & \multirow[b]{2}{*}{ Weight } & \multirow{2}{*}{$\begin{array}{c}\text { Risk Ratio } \\
\text { M-H, Fixed, 95\% Cl }\end{array}$} & \multirow{2}{*}{\multicolumn{3}{|c|}{$\begin{array}{c}\text { Risk Ratio } \\
\text { M-H, Fixed, } 95 \% \mathrm{Cl}\end{array}$}} & & \\
\hline & Events & Total & Events & Total & & & & & & & \\
\hline Battaglia 1989 & 29 & 159 & 30 & 157 & $33.8 \%$ & $0.95[0.60,1.51]$ & & & 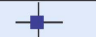 & & \\
\hline Bes 1999 & 8 & 36 & 10 & 36 & $11.2 \%$ & $0.80[0.36,1.79]$ & & & $\rightarrow-1$ & & \\
\hline Brola 1997 & 2 & 43 & 0 & 40 & $0.6 \%$ & $4.66[0.23,94.18]$ & & & & & \\
\hline Felisati 2002 & 1 & 44 & 2 & 45 & $2.2 \%$ & $0.51[0.05,5.44]$ & & & & & \\
\hline Saletu 1995 & 8 & 56 & 6 & 56 & $6.7 \%$ & $1.33[0.49,3.59]$ & & & & & \\
\hline Winblad 2001 & 29 & 177 & 32 & 169 & $36.6 \%$ & $0.87[0.55,1.37]$ & & & & & \\
\hline Total $(95 \% \mathrm{Cl})$ & & 623 & & 611 & $100 \%$ & $0.92[0.70,1.21]$ & & & & & \\
\hline Total events & 83 & & 88 & & & & & & & & \\
\hline
\end{tabular}

Figure 2 Results of meta-analysis, all withdrawals: nicergoline versus placebo. 
for study withdrawals are shown in tables 2. Results of meta-analysis showed a non-significant lower rate of withdrawals from nicergoline compared with placebo $(\mathrm{p}=0.57)$ and other active agents $(\mathrm{p}=0.28)$. For withdrawals due to $\mathrm{AE}$, the withdrawal rate was slightly higher with nicergoline when compared with placebo but the difference was only apparent and non-significant $(\mathrm{p}=0.7)$.

\section{Adverse events}

There were adequate data to perform meta-analysis for safety outcomes including any AE, SAE, diarrhoea, hot flushes, gastric upset, itching, hypertension, headache, dizziness, anxiety, insomnia, drowsiness and fatigue (see online supplementary table S1). However, there was no reference to cases with fibrosis and/or ergotism.

The meta-analysed risk ratios between nicergoline and other comparators and their corresponding 95\% CIs for study withdrawals and safety outcomes are shown in tables 2 and 3, respectively. Results of meta-analysis showed a nonsignificant lower rate of withdrawals from nicergoline compared with placebo $(\mathrm{p}=0.57)$ and other active agents $(\mathrm{p}=0.28)$. For withdrawals due to $\mathrm{AE}$, the withdrawal rate was slightly higher with nicergoline when compared with placebo but again the difference was non-significant $(\mathrm{p}=0.7)$.

The risk of any $\mathrm{AE}$ was similar with nicergoline compared with placebo (10 studies), ergot derivatives and other active comparators, all comparisons being nonsignificant. Risk of any SAE was slightly lower in the nicergoline group compared with placebo, but was nonsignificant. A significantly lower risk of agitation/anxiety was reported with nicergoline as compared with placebo $(p=0.01)$. Nicergoline was associated with a lower risk of diarrhoea as compared with placebo or ergot derivatives, with both comparisons being non-significant. The incidence of dizziness was similar in the nicergoline group as compared with placebo or other active agents. A comparatively lower risk of drowsiness was reported with nicergoline compared with placebo but the difference was non-significant. Risk of gastric upset was similar in the nicergoline and placebo groups.

Higher risk of fatigue was associated with nicergoline compared with active comparators including ergot derivatives but the difference was non-significant. Higher risk of hot flushes was reported with nicergoline compared with other comparators. Risk of headache and hypotension was higher with nicergoline compared with placebo. Higher risk of insomnia and itching was reported with nicergoline. For none of the AEs, where risk was higher for the nicergoline group, was any significant difference observed compared with the other intervention or placebo (figure 3).

Of the 14 studies included in the qualitative analysis, no incidence of AEs was reported in 8 studies during the entire study duration, while remaining studies reported excellent or good tolerability in nicergoline treated patients. None of these studies reported any incidence of ergotism or fibrosis with nicergoline.

\section{DISCUSSION}

Nicergoline is a potent and selective $\alpha-1 \mathrm{~A}$ adrenergic receptor antagonist. ${ }^{36}$ Nicergoline is reported to enhance catecholaminergic turnover, ${ }^{3}$ stimulate cholinergic neurotransmission, ${ }^{4}$ stimulate the phosphoinositide pathway, ${ }^{3}$ promote cerebral metabolic activity ${ }^{37}$ and has neuroprotective and antioxidant properties. ${ }^{38}$ Nicergoline is used clinically to improve the apathy and affective disorders caused by cerebral infarction (such as reduced mental alertness, inattention, impairment of recent memory, hypobulia, depression, etc). It is useful in the treatment of acute and chronic peripheral circulation disorders (such as obliterative vascular disease of the limbs, Raynaud's syndrome and other peripheral circulation dysfunction symptoms). Nicergoline has also been prescribed for the treatment of vascular dementia, especially for the improvement in cognitive dysfunction and memory, and to reduce the severity of this disease.

In addition, studies have been reported showing the usefulness of nicergoline in conditions such as posthaemodialysis pruritus, tinnitus and vertigo, ocular conditions such as arterial obstructions, venous thrombosis, diabetic retinopathies, senile macular degenerations, papilla ischaemic oedema and central serous chorioretinopathies. Dosages for known conditions are usually administered at $5-10 \mathrm{mg}$ three times a day, however antiaging preventative purposes may limit this to $5 \mathrm{mg}$ once or twice a day. Higher doses of up to $60 \mathrm{mg} /$ day have also been prescribed in clinical practice but have been associated with increased risk of AEs. ${ }^{4}$

The EMEA's Committee for Medicinal Products for Human Use (CHMP), in its recommendations, has suggested that ergot containing medicines, including nicergoline, should no longer be used to treat conditions involving blood circulation problems (such as peripheral artery disease, Raynaud's syndrome and retinopathies of vascular origin), memory and sensation problems and migraine headaches. This recommendation has been supported by the EMEA citing that these ergot derivatives have a high likelihood of causing SAEs such as fibrosis and ergotism. ${ }^{5}$ However, in this recommendation, the EMEA suggests that healthcare professionals can continue prescribing nicergoline and other ergot derivatives in dementia (including Alzheimer's disease) and acute migraine.

Nicergoline has proven efficacy in the treatment of senile dementia of Alzheimer type and multi-infarct dementia. ${ }^{1} 32$ Also, nicergoline has shown efficacy in conditions like posthaemodialysis pruritus, ${ }^{39}$ tinnitus and vertigo. ${ }^{40}$ Nicergoline has a positive effect on cognition and behaviour in addition to an effect on clinical global impression in older patients with mild-to-moderate cognitive and behavioural impairment of various clinical origins including chronic cerebrovascular disorders and Alzheimer's dementia. ${ }^{1}$

Nicergoline has been reported to cause central nervous system disturbances including diaphoresis, sleep disturbances, fainting, agitation, drowsiness, dizziness, insomnia, 
Table 2 Meta-analysis of withdrawal rate across included studies

\begin{tabular}{llllllll}
\hline & & & & & \multicolumn{2}{l}{ Fixed effects } \\
\cline { 5 - 8 } Outcome & Intervention & Comparator & Studies & $\mathbf{N}$ & RR (95\% Cl) & $\mathbf{p ~ V a l u e ~}$ & $\mathbf{I}^{\mathbf{2}}$ (\%) \\
\hline Total withdrawals & Nicergoline & Placebo & 8 & 1234 & $0.92(0.70$ to 1.21$)$ & 0.57 & 0 \\
Withdrawals due to AE & Nicergoline & Active agents & 3 & 201 & $0.45(0.10$ to 1.95$)$ & 0.28 & 18 \\
\hline
\end{tabular}

${ }^{*} \mathrm{RR}$ value greater than 1 denotes higher rate of AEs with nicergoline compared with the comparator drug and a value less than 1 denotes vice versa.

$\mathrm{AE}$, adverse event.

restlessness, flushing and increased appetite. ${ }^{8} 22$ Cardiovascular events like temporary rise in blood pressure, syncope, bradycardia and hypotension have been reported with nicergoline in a few studies. ${ }^{18} 41$

Nicergoline has been known to cause minor gastrointestinal side effects such as heartburn and abdominal pain, gastric pain, pyrosis, vomiting and diarrhoea. Various studies have reported other minor effects with nicergoline including hot flushes, dizziness, ejaculation failure and interstitial nephritis. ${ }^{42} 43$

Results of this meta-analysis showed the comparable safety profile of nicergoline with other active agents (including ergot derivatives) and placebo. The withdrawal rates and withdrawal due to AEs were similar with nicergoline compared with placebo and active agents. Incidence of any $\mathrm{AE}$ when compared with placebo and ergot derivatives was slightly higher in the nicergoline group but the difference was non-significant. Significantly lower rates of anxiety were reported with nicergoline compared with placebo $(p=0.01)$. Incidence of AEs such as diarrhoea, dizziness, drowsiness, gastric upset and fatigue was slightly lower with nicergoline as compared with placebo but the difference was nonsignificant for all comparisons.

Nicergoline was associated with higher rates of hot flushes, headache, hypotension, insomnia and itching. None of the comparisons showed a significant difference, but some of these AEs are probably because of the vasodilation action of nicergoline. Higher doses of nicergoline $(60 \mathrm{mg} /$ day) were associated with higher rates of AEs compared with the $30 \mathrm{mg} /$ day dosing, but the difference was not significant. None of the studies included in this meta-analysis reported any incidence of fibrosis or ergotism with nicergoline.

In its current recommendation, the EMEA has overlooked the efficacy and safety profile of nicergoline and has cautioned against its use in conditions with blood circulation problems, memory and sensation problems and migraine headaches. The CHMP at EMEA suggested a ban on use of ergot derivatives as they have

Table 3 Meta-analysis of overall AEs

\begin{tabular}{|c|c|c|c|c|c|c|c|}
\hline \multirow[b]{2}{*}{ Outcome } & \multirow[b]{2}{*}{ Intervention } & \multirow[b]{2}{*}{ Comparator } & \multirow[b]{2}{*}{ Studies } & \multirow[b]{2}{*}{$\mathbf{N}$} & \multicolumn{3}{|l|}{ Fixed effects } \\
\hline & & & & & RR (95\% Cl) & p Value & $I^{2}(\%)$ \\
\hline Any $A E$ & Nicergoline & Placebo & 10 & 1448 & $1.05(0.93 \text { to } 1.20)^{*}$ & 0.42 & 0 \\
\hline Any $A E$ & Nicergoline & Active agents & 4 & 292 & $1.19(0.71 \text { to } 2.01)^{*}$ & 0.51 & 5 \\
\hline Any $A E$ & Nicergoline & Ergot derivatives & 2 & 200 & $1.22(0.63 \text { to } 2.34)^{\star}$ & 0.56 & 19 \\
\hline Any SAE & Nicergoline & Placebo & 2 & 482 & 0.85 (0.50 to 1.45$)$ & 0.54 & 35 \\
\hline Anxiety & Nicergoline & Placebo & 2 & 482 & 0.59 (0.39 to 0.88$)$ & 0.01 & 0 \\
\hline Diarrhoea & Nicergoline & Placebo & 2 & 188 & 0.85 (0.24 to 3.05$)$ & 0.8 & 0 \\
\hline Diarrhoea & Nicergoline & Ergot derivatives & 2 & 200 & 0.99 (0.14 to 6.92$)$ & 0.99 & 0 \\
\hline Dizziness & Nicergoline & Placebo & 3 & 260 & $0.63(0.15$ to 2.57$)$ & 0.51 & 0 \\
\hline Dizziness & Nicergoline & Active agents & 2 & 116 & $1.00(0.18 \text { to } 5.58)^{*}$ & 1.0 & 0 \\
\hline Drowsiness & Nicergoline & Placebo & 2 & 442 & 0.34 (0.05 to 2.12$)$ & 0.24 & 0 \\
\hline Fatigue & Nicergoline & Placebo & 2 & 378 & $0.71(0.14$ to 3.53$)$ & 0.68 & 18 \\
\hline Fatigue & Nicergoline & Active agents & 3 & 260 & $1.24(0.35 \text { to } 4.47)^{\star}$ & 0.74 & 0 \\
\hline Fatigue & Nicergoline & Ergot derivatives & 2 & 200 & $1.79(0.40 \text { to } 7.98)^{*}$ & 0.45 & 0 \\
\hline Gastric upset & Nicergoline & Placebo & 6 & 1037 & 0.94 (0.58 to 1.52$)$ & 0.8 & 0 \\
\hline Hot flushes & Nicergoline & All comparisons & 3 & 470 & 3.65 (0.61 to 21.93$)$ & 0.16 & 0 \\
\hline Headache & Nicergoline & Placebo & 5 & 1004 & $1.28(0.63 \text { to } 2.60)^{\star}$ & 0.24 & 0 \\
\hline Hypotension & Nicergoline & Placebo & 2 & 378 & $1.49(0.26 \text { to } 8.72)^{\star}$ & 0.66 & 0 \\
\hline Insomnia & Nicergoline & Placebo & 3 & 498 & $1.81(0.39 \text { to } 8.29)^{*}$ & 0.45 & 0 \\
\hline Itching & Nicergoline & All comparisons & 2 & 108 & $3.23(0.35 \text { to } 30.08)^{\star}$ & 0.3 & 0 \\
\hline
\end{tabular}

${ }^{*} \mathrm{RR}$ value greater than 1 denotes higher rate of AEs with nicergoline compared with the comparator drug and a value less than 1 denotes vice versa.

$A E$, adverse event; $S A E$, serious $A E$. 


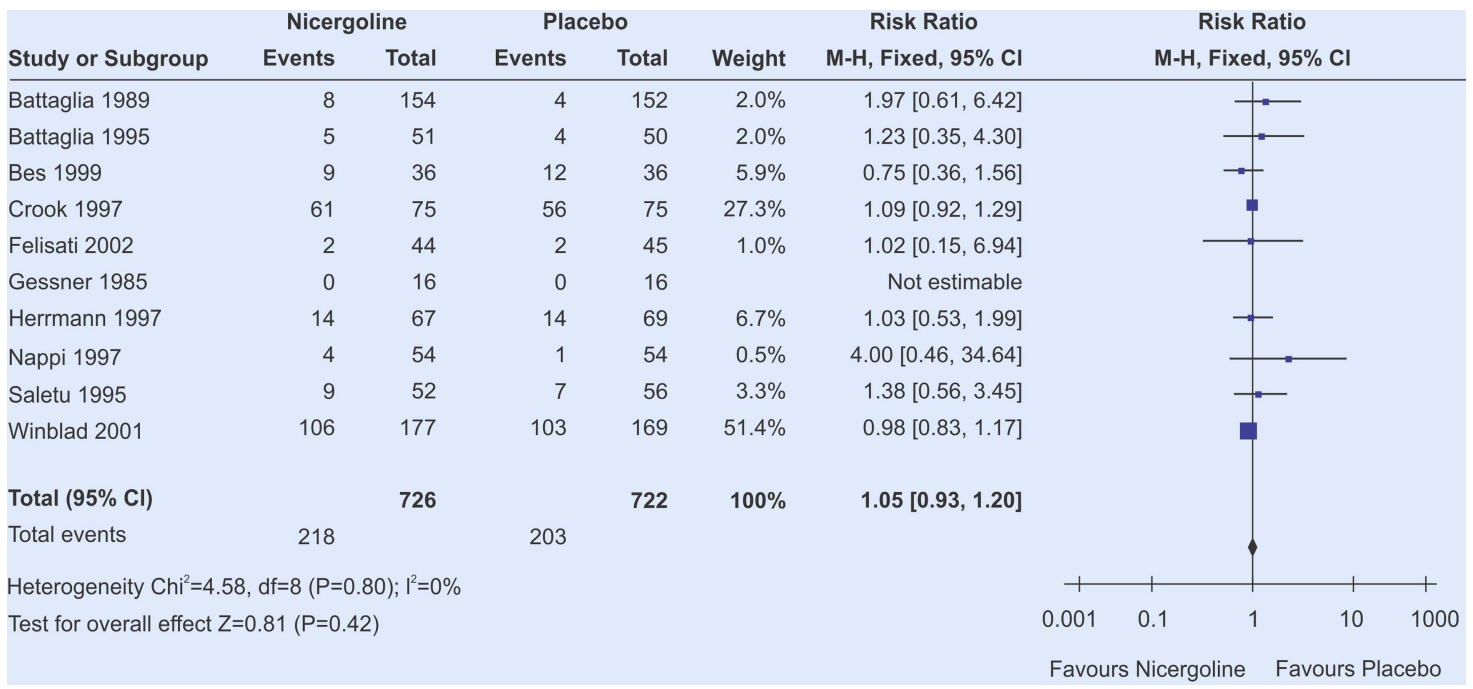

Figure 3 Results of meta-analysis, any adverse events: nicergoline versus placebo.

been associated with fibrosis and ergotism. The EMEA has probably considered the safety profile of all ergot derivatives as similar. The CHMP review has reported highest incidence of fibrosis and ergotism with dihydroergotamine and suggests incidence of these AEs with other ergot derivatives as well.

EMEA has suggested that echocardiography should be performed within 3-6 months of starting treatment with ergot derivatives and subsequently at 6 -12-month interval. ${ }^{44}$ In the current meta-analysis, most of the included studies were $>3$ and up to 24 months in duration and none of the included studies reported any incidence of fibrosis or ergotism with nicergoline. There is no evidence in literature to suggest any incidence of fibrosis and ergotism with nicergoline.

The strengths of this systematic review include the clear definition of the research question, adherence to an explicit research protocol that was developed prior to the analysis, the comprehensive nature of the data search (employing electronic databases and manual bibliography searches resulting in the inclusion of all relevant publications), consensus between two reviewers of all data elements prior to entry into the database and the quality control review of every element of this report. In addition, the quality of the studies and manuscripts used to provide data was relatively high. Only RCTs were included in this systematic review/ meta-analysis. The main limitation of this meta-analysis is the scarcity of head-to-head trials to compare the safety of nicergoline with other ergot derivatives. Another possible limitation of this review could be the publication timeframe of the included studies. Most of the studies were published in the 1980s and 1990s. There were hardly any trials published in recent years on safety evaluation for nicergoline.

\section{CONCLUSIONS}

This systematic review and meta-analysis has included the evidence to date with regard to tolerability and safety of nicergoline as reported by RCTs. Nicergoline is categorised under ergot derivatives. However, the AEs with nicergoline are mild and transient unlike other ergot derivatives (ergotamine and ergotoxine) which have been associated with fibrosis and ergotism.

The results from this systematic review/meta-analysis suggest that nicergoline has a comparable safety profile as placebo and other active comparators. None of the studies included in this systematic review reported any incidence of fibrosis or ergotism with nicergoline. The evidence generated by this review suggests that despite being an ergot derivative, nicergoline is a safe and well-tolerated drug. This systematic review/meta-analysis concludes that nicergoline is a safe option for therapeutic management in patients with dementia and cerebrovascular disorders.

\section{Author affiliations}

${ }^{1}$ Department of Neurology and Psychiatry, University Hospital, Umberto I, University of Rome, Sapienza, Italy

${ }^{2}$ Department of Molecular \& Internal Medicine, Hiroshima University Hospital, Hiroshima, Japan

${ }^{3}$ Jiangsu Province Geriatric Hospital, Jiangsu, China

${ }^{4}$ Hyderabad, Andhra Pradesh, India

Contributors AG carried out the searches in various databases. AG and JX carried out the filtration of citation and data extraction. MF and TN helped to draft the manuscript and reviewed it. All authors read and approved the final manuscript.

Funding This research received no specific grant from any funding agency in the public, commercial or not-for-profit sectors.

\section{Competing interests None.}

Provenance and peer review Not commissioned; externally peer reviewed.

Data sharing statement In addition to the manuscript, the corresponding author also has initial results of publication analysis. That explains the reason for inclusion and exclusion of individual studies. If readers require additional data on the analysis or the medical merits of the molecule, they can write to amitgarg.pharm@gmail.com.

Open Access This is an Open Access article distributed in accordance with the Creative Commons Attribution Non Commercial (CC BY-NC 3.0) license, which permits others to distribute, remix, adapt, build upon this work noncommercially, and license their derivative works on different terms, provided the original work is properly cited and the use is non-commercial. See: http:// creativecommons.org/licenses/by-nc/3.0/ 


\section{REFERENCES}

1. Fioravanti M, Flicker L. Efficacy of nicergoline in dementia and other age associated forms of cognitive impairment. Cochrane Database Syst Rev 2001;(4):CD003159.

2. Carfagna N, Di Clemente A, Cavanus S, et al. Modulation of hippocampal $\mathrm{ACh}$ release by chronic nicergoline treatment in freely moving young and aged rats. Neurosci Lett 1995;197:195-8.

3. Carfagna N, Rossi A. Nicergoline: biochemical studies on neuronal metabolism. Funct Neurol 1989;4:177-85.

4. Winblad B, Fioravanti M, Dolezal T, et al. Therapeutic use of nicergoline. Clin Drug Investig 2008;28:533-52.

5. New restrictions on use of medicines containing ergot derivatives. http://www.ema.europa.eu/docs/en_GB/document_library/Press_ release/2013/06/WC500144861.pdf

6. Jadad AR, Moore A, Carroll D, et al. Assessing the quality of reports of randomized clinical trials: is blinding necessary? Control Clin Trials 1996;17:1-12.

7. Arrigo A, Moglia A, Borsotti L. A double-blind, placebo-controlled, crossover trial with nicergoline in patients with senile dementia. Int Clin Pharmacol Res 1982;2:33-41.

8. Battaglia A, Bruni G, Ardia A, et al. Nicergoline in mild to moderate dementia. A multicenter, double-blind, placebo-controlled study. J Am Geriatr Soc 1989;37:295-302.

9. Battalgia A, Bruni $G$, Sacchetti $G$, et al. A double-blind randomized study of two ergot derivatives in mild to moderate dementia. Cur Therap Res 1990;48:597-612.

10. Battaglia A, Annoni K, Pamparana F, et al. Nicergoline in the Long Term Treatment of Mild or Moderate Senile Dementia. A Multicenter Double-blind, Randomized, Placebo-controlled Trial. In 8th European College of Neuropsychopharmacology Congress: 30th September-4th October 1995; Venice.

11. Bes A, Orgogozo JM, Poncet M, et al. A 24-month, double-blind, placebo-controlled multicentre pilot study of the efficacy and safety of nicergoline $60 \mathrm{mg}$ per day in elderly hypertensive patients with leukoaraiosis. Eur J Neurol 1999;6:313-22.

12. Bossi L. Buflomedil and nicergolin in the treatment of acute cerebral ischaemia. A double-blind, randomized comparative study. Minerva Med 1985;76:1005-18.

13. Brola W. Evaluation of treatment outcome after nicergoline and pentoxifylline in patients with ischemic stroke. Przegl Lek 1997;54:79-82.

14. Cascone A, Liverta C, Pollini C. A double-blind trial of nicergolin and placebo in cerebral and peripheral cerebrovascular disturbance in the aged. Minerva Cardioangiol 1978;26:95-100.

15. Colombeau P, Ballanger P. Results of the double-blind use of an alpha blockader, nicergoline, in cervico-prostatic dysfunctions. J Urol 1987:93:533-5.

16. Crook TH. Nicergoline in the treatment of probable Alzheimer's disease preliminary results of a double-blind, randomized, placebo-controlled study. J Neurol Sci 1997;150:S18.

17. Dubreuil C. Therapeutic trial in acute cochlear deafness. A comparative study of Ginkgo biloba extract and nicergoline. Presse Med 1986;15:1559-61.

18. Felisati G, Battaglia A, Papini MG, et al. Nicergoline in balance alterations in adult and elderly patients: a double-blind, placebo-controlled study. Clin Drug Investig 2002;22:731-40.

19. Forette F, Varin D, Henry JF, et al. Treatment of arterial hypertension in the elderly with an alpha-blocker: nicergoline (author's transl). La Nouvelle Presse Méd 1980;9:3685-8.

20. Gessner B, Voelp A, Klasser M. Study of the long-term action of a Gingkgo biloba extract on vigilance and mental performance as determined by means of quantitative pharmaco-EEG and psychometric measurements. Arzneimittelforschung 1985;35:1459-65.

21. Herrmann WM. A multicenter randomized double-blind study on the efficacy and safety of nicergoline in patients with multi-infarct dementia. Dement Geriatr Cogn Disord 1997;8:9-17.

22. Kugler JE, Meurer-Krull BC. Electroencephalography and psychometric measurements during the treatment of cerebral insufficiency with nicergoline and dihydroergotamine mesylate. Arzneimittelforschung 1985;35:1865-70.

23. $\mathrm{Lu} \mathrm{JH}$. Nicergoline in treatment of vascular dementia: a consecutive, multicenter, double-blind clinical trial. Chin J Neurol 2001:88-91.

24. Marolda M, Fragassi N, Buscaino GA. Clinical evaluation of (-) eburnamonine in comparison with nicergoline in patients suffering from chronic brain ischemia. Eur Neurol 1978;17:159-66.

25. Materna F. Leading symptom vertigo: comparative study with flunarizine and nicergoline. Med Klin 1985;80:292-5.

26. Nakashima T, Hattori N, Okimoto M, et al. Nicergoline improves dysphagia by upregulating substance $\mathrm{p}$ in the elderly. Medicine 2011;90:279-83.

27. Nappi G, Bono G, Merlo P, et al. Long-term nicergoline treatment of mild to moderate senile dementia. Results of a multicentre, double-blind, placebo-controlled study. Clin Drug Investig 1997;13:308-16.

28. Nishiyama $Y$, Abe A, Ueda $M$, et al. Nicergoline increases serum substance $P$ levels in patients with an ischaemic stroke. Cerebrovasc Dis 2010;29:194-8.

29. Pilkowska E, Jakubowska T, Witkowska K, et al. Nicergoline in the treatment of patients after a mild ischemic stroke. Neurol Neurochir Pol 2002;36:1075-85.

30. Pogliani E, Della Volpe A, Ferrari R. Inhibition of human platelet aggregation by oral administration of nicergoline. A double blind study. Farmaco Prat 1975;30:630-40.

31. Ronchi F, Margonato A, Ceccardi R. Symptomatic treatment of benign prostatic obstruction with nicergoline: a placebo controlled clinical study and urodynamic evaluation. Urol Res 1982;10:131-4.

32. Saletu B, Paulus E, Linzmayer L, et al. Nicergoline in senile dementia of Alzheimer type and multi-infarct dementia: a double blind, placebo controlled, clinical and EEG/ERP mapping study. Psychopharmacology 1995;117:385-95.

33. Setyopranoto ISP. Role of nicergoline 60 miligram per oral for improvement of the patients with acute ischemic stroke. J Neurol Sci 2009;285:S221-2.

34. Winblad B, Bonura ML, Rossini BM, et al. Nicergoline in the treatment of mild-to-moderate Alzheimer's disease: a European multicentre trial. Clin Drug Investig 2001;21:621-32.

35. Zucconi V, Terzi Bolaffio M. Results with nicergolin and dihydroergotoxine in 30 hemiplegics in the postacute phase. Minerva Med 1974;65:936-45.

36. Alvarez-Guerra M, Bertholom N, Garay RP. Selective blockade by nicergoline of vascular responses elicited by stimulation of alpha $1 \mathrm{~A}$-adrenoceptor subtype in the rat. Fundam Clin Pharmacol 1999;13:50-8.

37. Shintomi K, Yoshimoto K, Ogawa Y, et al. Effects of nicergoline on cerebral energy metabolism in normal mice. Yakugaku Zasshi 1986;106:90-4.

38. Sortino MA, Battaglia A, Pamparana F, et al. Neuroprotective effects of nicergoline in immortalized neurons. Eur J Pharmacol 1999;368:285-90.

39. Bousquet J, Rivory JP, Maheut M, et al. Double-blind, placebo-controlled study of nicergoline in the treatment of pruritus in patients receiving maintenance hemodialysis. J Allergy Clin Immuno 1989;83:825-8.

40. Akisada T, Orita $Y$, Sato $Y$, et al. Effect of nicergoline on vertigo and tinnitus. Pract Otol 1994;87:845-55.

41. Boismare F, Lefrancois J. Haemodynamic effects of nicergoline in man at rest and during exercise. Clin Exp Pharmacol Physiol 1980;7:105-12.

42. Gallego J, Forner V, Jimenez F, et al. Nicergoline in the treatment of neuropathic bladder dysfunction: a preliminary report. Paraplegia 1984;22:216-24.

43. Kim MJ, Chang JH, Lee SK, et al. Acute interstitial nephritis due to nicergoline (Sermion). Nephron 2002;92:676-9.

44. Ergot-derived dopamine agonists: risk of fibrotic reactions in chronic endocrine uses. http://www.mhra.gov.uk/Safetyinformation/ DrugSafetyUpdate/CON087807 